\title{
ACUTE INTESTINAL OBSTRUCTION DUE TO MESENTERIC LYMPHANGIOMA
}

\author{
BY \\ B. M. L. UNDERHILL \\ From the Government Hospital, Bahrain
}

(RECEIVED FOR PUBLICATION MARCH 18, 1959)

The rarity of abdominal lymphangiomata is emphasized by Raiford (1932) who found only one example in 11,500 necropsies.

Willis (1953) quotes one case in a 4-year-old girl who had a history of recurrent abdominal pain for eight months. MacNab and Menzies (1950) found an example in an 18-year-old recruit and Wood (1955) reports two cases from Leicester, both in males, one 29 and one 8 years old. Standeven (1953) and Callaghan and Farley (1958) each describe one case of multiple mesenteric lymphatic cysts.

A comprehensive review of the condition was given by Levene, Walker and White (1956) when they published an account of two male children, one 12 and one 4 in whom a mesenteric lymphangioma gave rise to acute abdominal symptoms. These children presented with abdominal colic of one or two days' duration but in only one of the cases mentioned above was there complete intestinal obstruction.

This unusual mode of presentation makes the following case worthy of record.

\section{Case Report}

A 7-year-old Arab boy was admitted to the Bahrain Government Hospital on March 23, 1958. His father said that he had been thin for some time but had been ill only for three days during which there had been vomiting and constipation and the child's abdomen had increased to an enormous size. The father was adamant in his statement that the boy's abdomen had been of normal size until three days previously.

The patient presented a bizarre appearance. He was a thin, desperately ill little boy adherent to the back of a vast distended abdomen over which the skin was tightly stretched. Veins of the abdominal wall were grossly distended. There appeared to be two very large coils of intestine crossing the abdomen from left to right but no peristalsis could be seen in them though bowel sounds were loud and tinkling. In fact, these 'coils' proved to be the cyst bisected across its middle by a band of ileum.

Transfusion with dextrose-saline solution was begun and gastric suction instituted through a Ryle's tube. After a few hours of this treatment, the child's condition had improved and laparotomy was undertaken.

The abdomen was opened through a long right paraumbilical incision and the swelling was found to consist of an enormous purple mesenteric cyst approximately 10 by 8 in. ( 25 by $20 \mathrm{~cm}$.). Over the cyst a tape-like loop of ileum was tightly stretched. Obstruction was complete and proximal coils of intestine were distended. The loop of stretched gut and the cyst were excised as a $\mathrm{V}$ wedge and end-to-end anastomosis was performed. No other abnormalities were found.

Apart from a mild and transient wound infection, convalescence was uncomplicated. The child began to put on weight and became a gay and happy little boy. He was discharged on the sixteenth post-operative day. Unfortunately, as he was taken straight back to his home in Saudi Arabia, follow-up has been impossible.

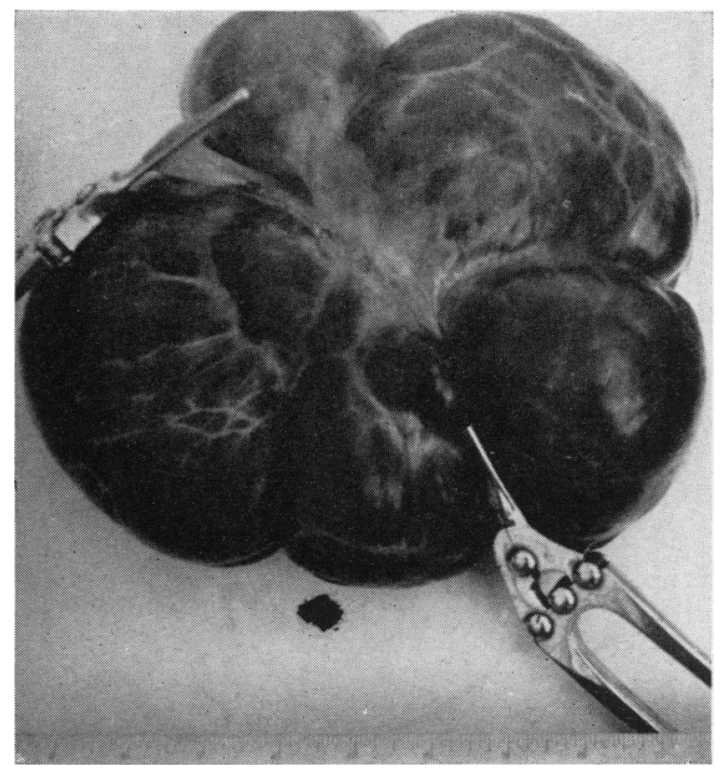

FIG. 1.-The clamps are attached to the ends of the flattened ileal loop which bisects the specimen. 
Histological Report (Dr. Stallybrass). 'The specimen consists of a multilocular thin-walled cyst containing brown fluid and many cholesterol crystals. The intestinal wall is normal except for numerous lymph spaces in the sub-serosa. The sub-serosa is continuous with the cyst lining. There are many lipoid crystals in the wall and the appearance is characteristic of mesenteric lymphangioma.'

The gross appearance of the specimen is shown in Fig. 1.

\section{Discussion}

Willis (1953) regards these tumours as being congenital rather than neoplastic in nature and considers that fluid accur ulation and progressive formation of collateral channels with supervening thrombosis and organization are enough to account for their increase in size. Very rapid increase in volume is not unusual due to dilatation of the abdominal spaces following torsion, inflammation or pressure changes. Such dilatation must have taken place in this case bringing about complete obliteration of the ileal lumen as it passed over the cyst.

Fortunately these lesions are completely benign so that excision is curative. A length of intestine has usually to be excised with the cyst which cannot be shelled out without vascular destruction.

\section{REFERENCES}

Callaghan, R. P. and Farley, D. L. B. (1958). Brit. J. Surg., 45, 655. Levene, M., Walker, P. A. and White T. A. (1956). Arch. Dis. Childh., 31, 502

MacNab, T. and Menzies, T. (1950). Brit, J. Surg., 37, 294.

Raiford, T. S. (1932). Arch. Surg. (Chicago), 25, 122.

Standeven, A. (1953). Brit. J. Surg.. 41, 102.

Willis, R. A. (1953). Pathology of Tumours, 2nd ed. Butterworth. London.

Wood, K. (1955). Brit. J. Surg., 43, 304. 